Article

\title{
Global Trends in Phytohormone Research: Google Trends Analysis Revealed African Countries Have Higher Demand for Phytohormone Information
}

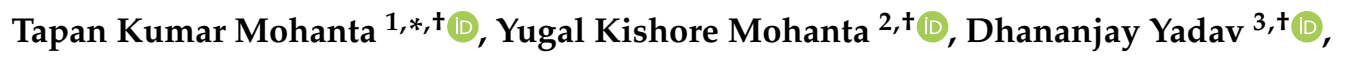 \\ Abeer Hashem ${ }^{4,6}$, Elsayed Fathi Abd_Allah ${ }^{5}$ (D) and Ahmed Al-Harrasi 1,* \\ 1 Natural and Medical Sciences Research Center, University of Nizwa, Nizwa 616, Oman \\ 2 Department of Botany, North Orissa University, Sri Ramchandra Vihar, Takatpur, Baripada, \\ Odisha 757003, India; ykmohanta@gmail.com \\ 3 Department of Medical Biotechnology, Yeungnam University Gyeongsan, Gyeongsangbuk-do 38541, Korea; \\ dhanyadav16481@gmail.com \\ 4 Botany and Microbiology Department, College of Science, King Saud University, \\ Riyadh 11451, Saudi Arabia; habeer@ksu.edu.sa \\ 5 Plant Production Department, College of Food and Agricultural Sciences, King Saud University, \\ Riyadh 11451, Saudi Arabia; eabdallah@ksu.edu.sa \\ 6 Mycology and Plant Disease Survey Department, Plant Pathology Research Institute, ARC, Giza 12511, Egypt \\ * Correspondence: nostoc.tapan@gmail.com (T.K.M.); aharasi@unizwa.edu.om (A.A.-H.) \\ + These authors contributed equally to this work.
}

Received: 10 June 2020; Accepted: 31 August 2020; Published: 22 September 2020

\begin{abstract}
The lines of research conducted within a country often reflect its focus on current and future economic needs. Analyzing "search" trends on the internet can provide important insight into predicting the direction of a country in regards to agriculture, health, economy, and other areas. 'Google Trends' collects data on search terms from different countries, and this information can be used to better understand sentiments in different countries and regions. Agricultural output is responsible for feeding the world and there is a continuous quest to find ways to make agriculture more productive, safe, and reliable. The application of phytohormones has been used in agriculture world-wide for many years to improve crop production and continues to be an active area of research for the application in plants. Therefore, in the current study, we searched 'Google Trends' using the phytohormone search terms, abscisic acid, auxins, brassinosteroids, cytokinin, ethylene, gibberellins, jasmonic acid, salicylic acid, and strigolactones. The results indicated that the African country Zambia had the greatest number of queries on auxin research, and Kenya had the most queries in cytokinin and gibberellin research world-wide. For other phytohormones, India had the greatest number of queries for abscisic acid and South Korea had the greatest number of ethylene and jasmonic acid search world-wide. Queries on salicylic acid have been continuously increasing while the least number of queries were related to strigolactones. Only India and United States of America had significant numbers of queries on all nine phytohormones while queries on one or more phytohormones were absent in other countries. India is one of the top five crop-producing countries in the world for apples, millet, orange, potato, pulses, rice, sugarcane, tea, and wheat. Similarly, the United States of America is one of the top five crop-producing countries of the world for apples, grapes, maze, orange, potato, sorghum, sugarcane, and wheat. These might be the most possible factors for the search queries found for all the nine phytohormones in India and the United States of America.
\end{abstract}

Keywords: pytohormones; abscisic acid; auxin; brassinosteroids; cytokinin; ethylene; gibberellins; jasmonic acid; salicylic acid; strigolactones; Google trends 


\section{Introduction}

Phytohormones are a group of chemical substances found in the plants that regulate growth, development, organogenesis, and stress responses in plants [1-6]. Phytohormones play an active and critical role in all stages of plant development, from seed germination [7], to root [8], shoot [9], leaf [10], stem development [11], flowering [12], fruiting [13] and ripening [14-16]. Plant hormones function as an important signaling molecules [2] and are synthesized in a genetically programmed manner throughout the lifecycle of a plant. Each and every individual cell of a plant is capable of producing and transporting hormones to the specific tissues and organs [17-20]. Phytohormones are also present in algae [21,22], fungi [23-25], and bacteria [26-28], which often form a symbiotic relationship with the host plants or combined in the case of lichens to create a unique form of plant life. The variety of demonstrated phytohormones commonly found in plants are abscisic acid, auxins, brassinosteroids, cytokinin, ethylene, gibberellins, jasmonic acid, salicylic acid, and strigolactones. Abscisic acid is generally recognized as a growth inhibitor and was previously known as dormin/abscicin II [29,30].

Phytohormones play a crucial role in every aspect of plant growth and development, as well as stress responses. The controlled synthesis and coordinated homeostasis of these hormones regulate cellular metabolism in plants and their entire life cycle. The utilization of these hormones in agriculture and horticulture are of enormous importance and growers have been using these hormones for regulating various aspects of plant productivity since their first discovery and commercial availability [31,32]. A healthy plant is critical for maximizing yield and obtaining high quality harvested products [33,34]. Millions of hectares in the world are used to grow crops each year, and plant growth regulators are frequently used to increase the crop yields [35]. Their use increases the economic value by enhancing the quality and quantity of the crops [36]. Growth regulators can also be used to manipulate harvest dates to avoid losses in crop yield due to adverse environmental conditions $[15,37]$. Growth regulators are extensively used in the propagation of plants from stem cuttings, reducing the time required to generate the plants that can be used in field plantings [38]. Phytohormone treatments have an enormous potential to provide higher crop yields to address the food needs of the ever-increasing population in the world $[39,40]$. Good agricultural land space is limited, and the world population continues to increase, placing ever greater pressure on the ability to increase crop yields and grow crops on non-optimal land. The ability to develop a sufficient, reliable, and secure amount of food is a daunting task, and phytohormones have been used to help achieve this goal. A greater level of research is still needed; however, to achieve the most effective use of phytohormones.

Environmental, edaphic, and climatic conditions are not the same in all the locations where crops are produced. The climatic conditions vary considerably in the tropic, sub-tropic, temperate, and polar regions of the world, affecting the yields and the types of crops that can be grown. In addition, physical, chemical, biological, and anthropogenic activities (edaphic factor) of soils also play an important role in plant growth, development, stress responses, and ultimately crop yield. Currently, there are 253 countries in the world that are distributed in different climatic and edaphic regions, and among these countries, relatively few are agriculturally productive. The top five crop-producing countries of the world for various crops are mentioned in Table 1 [41].

From the above, it clearly shows that different countries represent varied climatic and edaphic regions in the world. Therefore, the cultivation of a specific crops, as well as their quality and quantities are largely dependent on the presence of a suitable environmental conditions. Therefore, some countries are highly productive, while others cannot compete with it. In addition, climatic and edaphic factors, advanced knowledge of science and the implementation of advanced technology in agriculture and research also play an important role. During the era of information technology, people (researchers, farmers, students, and consumers) want to obtain knowledge through the internet to implement this knowledge directly in agriculture and future research. Regarding the internet, the majority of computer users throughout the world use Google as the default search engine to search their queries [42,43]. Therefore, in the present study, we attempted to use 'Google Trends' to analyze the trends of people in 
different countries of the world in regards to phytohormones. Google dominates the search engines used on the internet and the term "Google" has become a routine and household word associated with internet browsing. Approximately 3.3 billion searches occur in Google each day and a total of 2 trillion Google searches were estimated for 2018 [44,45]. People use Google to search many topics, including health, practical information, online shopping, event booking, and other available online resources [46-48]. Therefore, Google search data provides a major advantage over traditional survey data. In addition, the use of 'Google Trends' enabled us to survey the weekly, monthly, and yearly use of phytohormone search queries without any cost.

Table 1. Top five crop-producing countries of the world [41].

\begin{tabular}{cc}
\hline Crops & Top 5 High Crop Producing Countries \\
\hline Apple & China, United States of America, Poland, Turkey, India \\
Barley & Russia, Germany, France, Ukraine, Australia \\
Buckwheat & Russia, China, Ukraine, France, Poland \\
Coffee & Brazil, Vietnam, Colombia, Indonesia, Ethiopia \\
Grapes & China, Italy, United States of America, France, Spain \\
Maize & United States of America, China, Brazil, Argentina, Mexico \\
Millet & India, Niger, China, Mali, Nigeria \\
Oat & Russia, Canada, Australia, Poland, Finland \\
Orange & Brazil, China, India, United States of America, Mexico \\
Potato & China, India, Russia, Ukraine, United States of America \\
Pulses & India, Poland, Mozambique, United Kingdom, Pakistan \\
Rice & China, India, Indonesia, Bangladesh, Vietnam \\
Rye & Germany, Russia, Poland, Belarus, Denmark \\
Sorghum & United States of America, Nigeria, Sudan, Mexico, Ethiopia \\
Triticale & Poland, Germany, Belgium, France, Russia \\
Sugarcane & Brazil, India, Thailand, China, United States of America \\
Sunflower & Ukraine, Russia, Argentina, China, Romania \\
Tea & China, India, Kenya, Sri Lanka, Vietnam \\
Wheat & China, India, Russia, United States of America, Canada \\
\hline
\end{tabular}

This analysis will enable us to better understand which countries are querying information on phytohormones and benefitting from their search queries regarding phytohormone research and implantation in agriculture production. In addition, it also enables us to understand which countries are lagging behind and need additional support on specific topics and applications. The "Google Trends" search engine is an excellent tool for assessing country by country trends in the use of search terms searched using the Google browser. An analysis of phytohormone query trends using 'Google Trends' will provide considerable information about the importance of phytohormone research globally.

\section{Results}

\subsection{Country-Wide Search Trends}

\subsubsection{India Leads in Abscisic Acid, and Zambia Leads in Auxin Search Queries}

In the present study, we searched and analyzed all the naturally-occurring phytohormones, including abscisic acid, auxin, brassinosteroids, cytokinin, ethylene, gibberellins, jasmonic acid, salicylic acid, and strigolactones. All 253 countries presently designated in the world were included in our analysis of query data from 1 January 2004 to 20 October 2019. Country-wide analysis using 'Google Trends' of different phytohormone-related queries by different countries revealed a spatiotemporal result (Figure 1). The countries with the greatest number of queries for abscisic acid using Google trends were India, Philippines, Australia, Canada, Thailand, the United States of America (USA), and the United Kingdom (UK) (Supplementary File 1). A total of 53 countries were associated with queries on auxin. A few of the countries with high query values for auxin were Zambia, Ethiopia, 
Nigeria, Nepal, Jamaica, Tanzania, Pakistan, New Zealand, India, South Korea, Malaysia, China, Vietnam, Kenya, and others (Supplementary File 2).
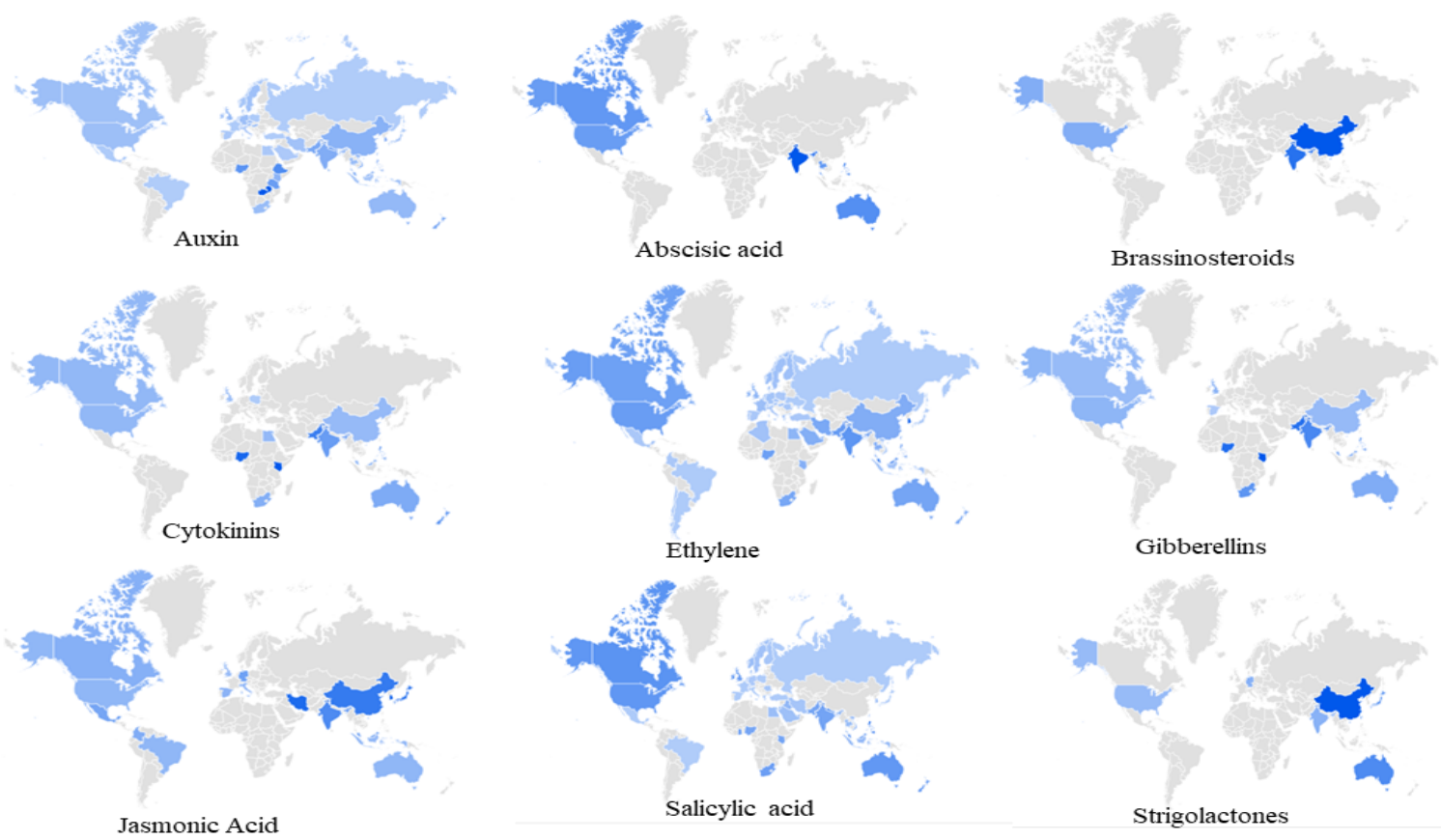

Figure 1. Global map of phytohormone search. The deep blue color indicates a high level of search query for the respective phytohormone, while the light blue color indicates a low search query. The map indicates data from 1 January 2004 to 20 October 2019.

\subsubsection{China Leads in Brassinosteroids and Kenya Leads in Cytokinin Search Queries}

Brassinosteroids are steroid hormones with $\mathrm{C}_{27}, \mathrm{C}_{28}$, and $\mathrm{C}_{29}$ carbon-containing compounds with substituted side chain alkyl groups. China was found to have the greatest number of search queries for Brassinosteroids followed by India and the USA (Figure 1, Supplementary File 3). No other countries were found to be associated with BRs search queries as determined with 'Google Trends'. The country with the greatest number of cytokinin search queries was Kenya, followed by Mauritius, Nigeria, Pakistan, New Zealand, India, Philippines, Australia, South Africa, Malaysia, Canada, USA, Egypt, China, UK, and Poland. No additional other countries were associated with cytokinin search queries (Figure 1, Supplementary File 4).

\subsubsection{South Korea Leads in Ethylene and Kenya Leads in Gibberellin Search Queries}

Among 253 countries, South Korea was found to have the greatest number of ethylene search queries, followed by Singapore, Malaysia, Qatar, India, Pakistan, USA, Canada, Nigeria, Lebanon, Taiwan, Philippines, Australia, United Arab Emirates (UAE), and others. In total, 60 countries were found to be associated with ethylene search queries (Figure 1, Supplementary File 5). In contrast, only 15 countries were found to be associated with gibberellin search queries. Kenya had the greatest number of queries followed by Nigeria, Pakistan, Jamaica, India, South Africa, Philippines, Australia, UK, Malaysia, USA, China, Canada, and Spain (Figure 1, Supplementary File 6). 


\subsubsection{South Korea Leads in Jasmonic Acid and Philippines Leads in Salicylic Acid Search Queries}

South Korea had the greatest number of jasmonic acid search queries followed by Iran, Japan, China, India, Germany, Mexico, Malaysia, Colombia, Canada, and others (Figure 1, Supplementary File 7). In total, 20 countries were found to be associated with jasmonic acid search queries in Google. In contrast, 53 countries were found to be associated with salicylic acid search queries. The Philippines had the greatest number of salicylic acid search queries followed by Trinidad and Tobago, Singapore, Nepal, Canada, USA, Australia, Ireland, Ghana, UK, South Africa, New Zealand, Malaysia, UAE, India, Sri Lanka, Kenya, Pakistan, and others (Figure 1, Supplementary File 8).

\subsubsection{China Lead in Strigolactones Search Queries}

China had the greatest number of strigolactones search queries among the 253 countries, followed by Taiwan, Australia, Japan, Germany, India, and the USA. No additional countries were found to be associated with strigolactones search queries (Figure 1, Supplementary File 9).

\subsection{Year-Wise and Total Number of Search Queries}

\subsubsection{Salicylic Acid Queries Are Increasing}

All of the data on phytohormone search trends from 1 January 2004 to 20 October 2019 were downloaded to analyzed yearly trends in phytohormone search queries. The results indicated that of the number of salicylic acid search queries was higher than for other phytohormones and that the number of salicylic acid queries was increasing yearly (Figures 2 and 3, Table 2, Supplementary File 10). The mean statistical values of the Google trend result over time for abscisic acid, auxin, brassinosteroids, cytokinin, ethylene, gibberellins, jasmonic acid, salicylic acid, and strigolactones were found to be 27.56, 31.61, 15.80, 27.53, 47.68, 23.16, 18.96, 50.62, and 16.51, respectively. Salicylic acid has the highest mean of 50.62 for search query, followed by 47.68 ethylene (Table 2). However, the standard deviation of ethylene (17.00) was highest among the others (Table 2). Frequency distribution showed brassinosteroids remained more concentrated towards the range of 0-15 while ethylene, cytokinin, and salicylic acid were more concentrated towards the range from 60-100 (Figure 3). However, the frequency distribution of the individual phytohormones was quite diverse, and the occurrence of distinct values in the variable was not so abundant. This explains the dynamic search trend of the phytohormones in Google.

The greatest number of queries for the salicylic acid trend was followed by queries on ethylene. Notably, the number of ethylene queries was the highest during the beginning of 2004 and has been gradually decreasing with time (Figure 2). The number of auxin queries followed the number of salicylic acid and ethylene queries. Notably, however, the number of auxin search queries was similar to the number for cytokinin at the present time (Figure 2). The number of queries on jasmonic acid was quite low. The lowest number of search queries; however, was for strigolactones (Figure 2). While the initial number of strigolactone queries was quite low in 2004, the number has been growing and strigolactones are receiving considerable attention at present. Regardless of the increase, however, the number of queries on strigolactones is still the lowest among all phytohormone search queries globally (Figure 2). The number of auxin and abscisic acid queries has remained quite stable with intermittent ups and downs. In contrast, the number of queries on gibberellins and jasmonic acid has been gradually decreasing over time (Supplementary Figure S1). 
Table 2. Statistical details of phytohormone search over different time.

\begin{tabular}{|c|c|c|c|c|c|c|c|c|c|}
\hline Statistical Parameters & Abscisic Acid & Auxin & Brassinosteroids & Cytokinin & Ethylene & Gibberellins & Jasmonic Acid & Salicylic Acid & Strigolactones \\
\hline Number of values & 190 & 190 & 190 & 190 & 190 & 190 & 190 & 190 & 190 \\
\hline Minimum & 13.00 & 16.00 & 0.0 & 12.00 & 27.00 & 9.000 & 6.000 & 28.00 & 0.0 \\
\hline $25 \%$ percentile & 20.00 & 25.00 & 8.000 & 21.00 & 36.00 & 15.00 & 11.00 & 40.00 & 9.000 \\
\hline Median & 25.00 & 29.00 & 12.00 & 24.00 & 42.00 & 18.00 & 14.00 & 48.00 & 17.00 \\
\hline $75 \%$ percentile & 30.25 & 37.00 & 17.00 & 31.00 & 53.00 & 25.00 & 20.00 & 55.00 & 22.00 \\
\hline Maximum & 100.0 & 100.0 & 100.0 & 100.0 & 100.0 & 100.0 & 100.0 & 100.0 & 100.0 \\
\hline Mean & 27.56 & 31.61 & 15.80 & 27.53 & 47.68 & 23.16 & 18.96 & 50.62 & 16.51 \\
\hline Standard deviation & 12.90 & 10.63 & 12.87 & 11.59 & 17.00 & 14.47 & 14.57 & 14.37 & 12.52 \\
\hline Standard error of mean & 0.9357 & 0.7715 & 0.9338 & 0.8410 & 1.234 & 1.050 & 1.057 & 1.042 & 0.9081 \\
\hline
\end{tabular}




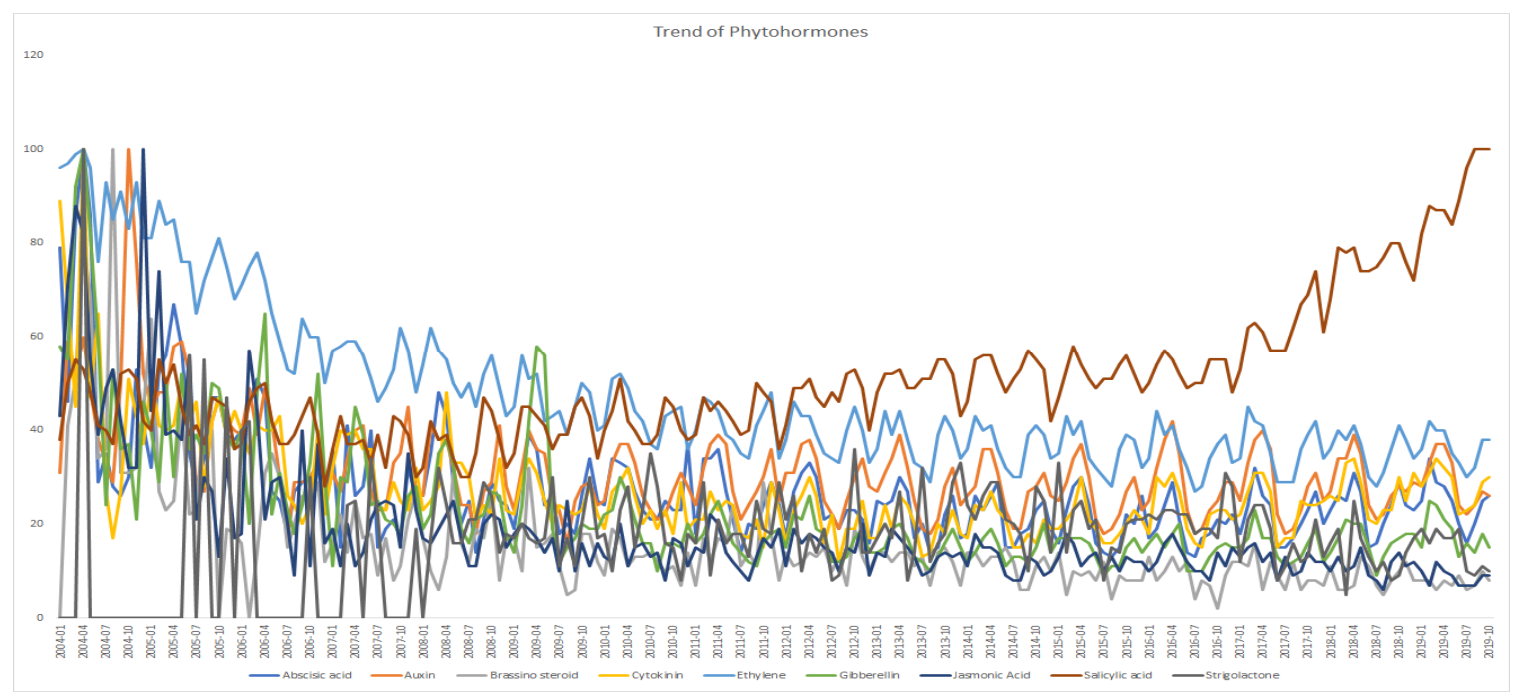

(A)

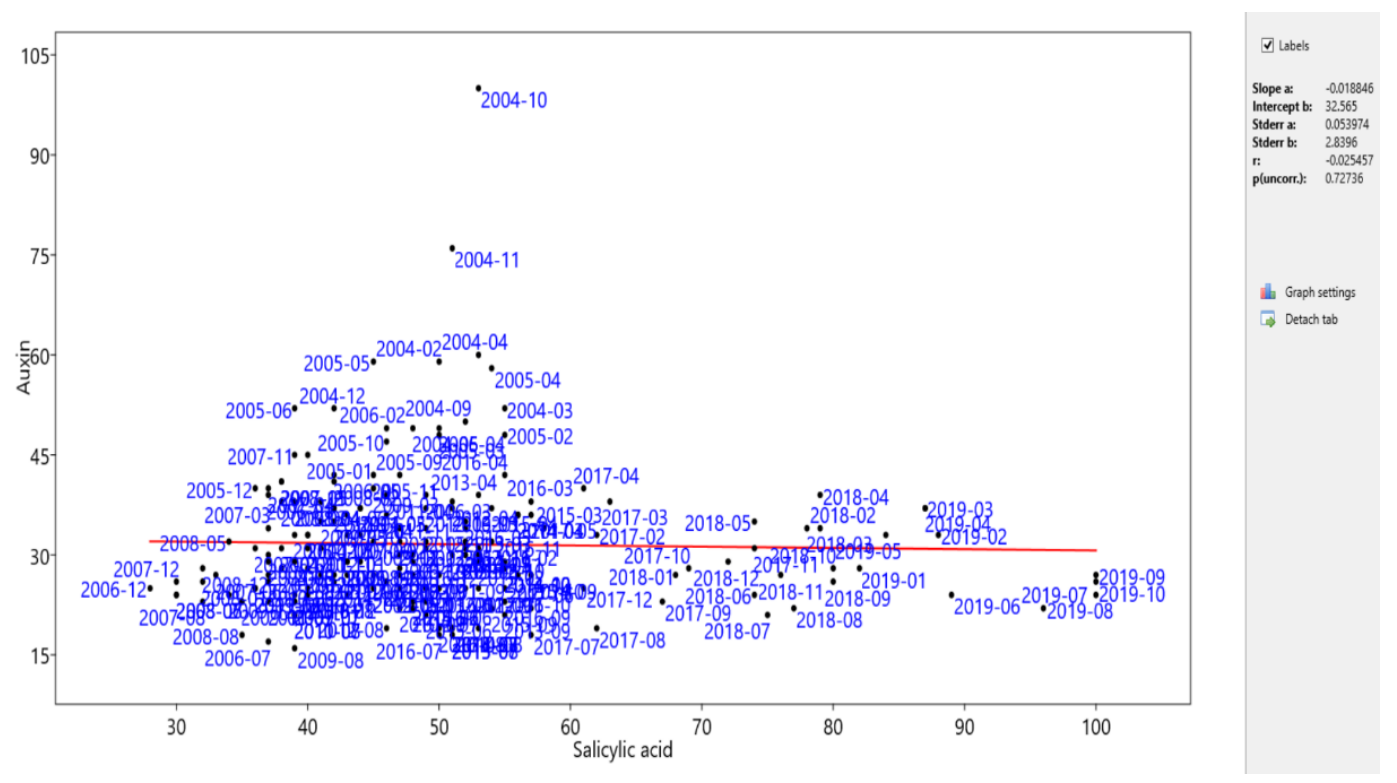

(B)

Figure 2. (A) Trends of phytohormone search queries from January 2004 to October 2019. The trend shows the search query for salicylic acid is continuously growing compared to other phytohormones. The search query for strigolactones was very low. In total, nine phytohormones, namely abscisic acid, auxin, brassinosteroids, cytokinin, ethylene, gibberellin, jasmonic acid, salicylic acid, and strigolactones were taken into consideration. (B) Regression analysis of salicylic acid with auxin showed negative correlation ( $\mathrm{y}=51.708-0.034 \mathrm{x}$, slope $a=-0.018, r=-0.025)$. The regression analysis of salicylic acid with other phytohormones are provided in Supplementary Figure S3. 


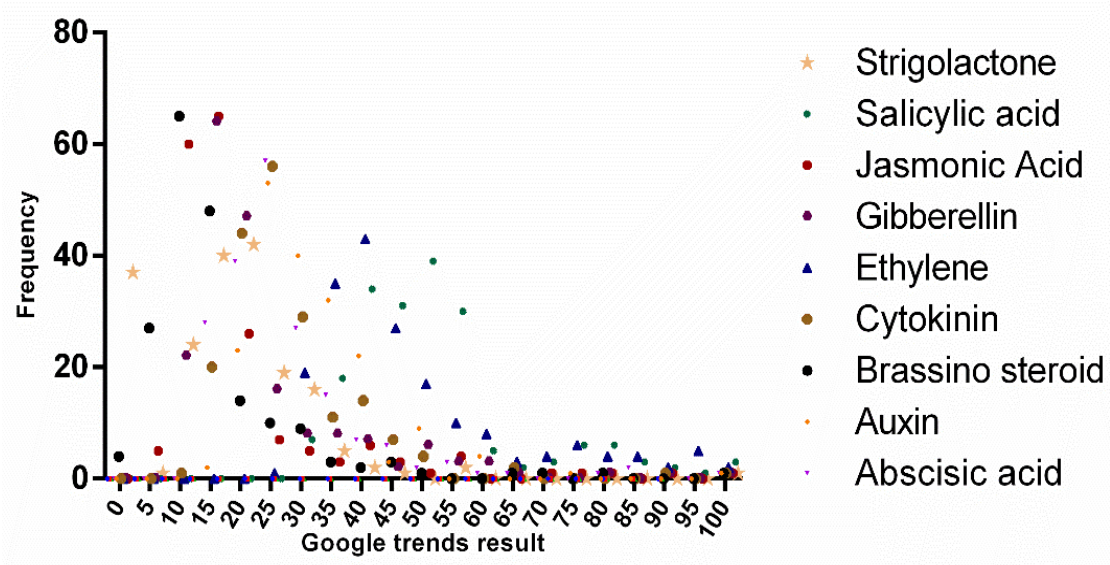

Figure 3. Frequency distribution of different phytohormones. Google trend search data over time was considered to draw the graph. The graph shows various phytohormone search results of Google trends found dynamically. However, a very few numbers of $(\sim<20)$ Google trend results were found with a score more than 35 .

2.2.2. Only India and The United States of America Had Search Queries for All of the Examined Phytohormones

A Venn diagram was constructed to compare the number of queries for the different phytohormones in different countries. A total of 15 different combinations of phytohormone search queries was examined (Supplementary Figure S2, Table 3). Only India and the United States of America were found to have search queries on all nine phytohormones (Figure 4, Supplementary File 11). As illustrated, the greatest share of queries on all nine phytohormones were associated with India and the USA (Figure 4). Search queries for one or more of the phytohormones were absent in the other countries. In addition to India and the USA, some of the countries with the highest and most comprehensive number of queries on the nine phytohormones included were Australia, Canada, China, Kenya, Malaysia, New Zealand, Nigeria, Pakistan, Philippines, South Africa, and the United Kingdom. Brassinosteroid queries were not associated with Australia, Canada, Kenya, Malaysia, New Zealand, Nigeria, Pakistan, Philippines, and the United Kingdom (Figure 4). A word cloud generated using all of the countries associated with phytohormone search queries showed India, USA, and the Philippines. Abscisic acid queries were absent in China, Malaysia, New Zealand, and Pakistan (Figure 5).

Gibberellin queries were not found for New Zealand, while jasmonic acid queries were absent in Kenya, New Zealand, Nigeria, Pakistan, and the Philippines (Figure 4). Salicylic acid queries were absent for China, while strigolactone queries were absent in Kenya, Malaysia, New Zealand, Nigeria, Pakistan, Philippines, and the United Kingdom. Queries on six common phytohormones (abscisic acid, auxin, cytokinin, ethylene, gibberellin, and salicylic acid) combined were only associated with six countries-India, the Philippines, Australia, Canada, United States of America, and the United Kingdom (Figure 4, Table 3). Queries on five common phytohormones (auxin, cytokinin, ethylene, gibberellin, and salicylic acid) were associated with Nigeria, Pakistan, Malaysia, Kenya, and South Africa (Figure 4, Table 3). The most common countries with ethylene search queries were Qatar, Kuwait, Algeria, Portugal, Colombia, Chile, Argentina, and Ukraine (Table 3). Auxin, ethylene, and salicylic acid queries were the most dominant and associated with 33 countries (Table 3).

Principal component analysis (PCA) was conducted of the countries associated with search queries on the nine phytohormones. Results indicated that India, Australia, the USA, Singapore, China, South Korea, Canada, Malaysia, Taiwan, Iran, and Japan fell distantly in coordinate 1; whereas, the United Kingdom, New Zealand, South Africa, Mauritius, Pakistan, Philippines, Nigeria, and Kenya fell distantly in coordinate 2 (Figure 6). In addition, African countries, including Kenya, Nigeria, South Africa, Zambia, and Ghana also fell in coordinate 2; whereas, no country was found to fall in coordinate 1 (Figure 6). 
Table 3. Venn diagram result of the common countries of phytohormone searches with different phytohormone combinations. Six phytohormones, auxin, abscisic acid, cytokinin, ethylene, gibberellins, and salicylic acid were taken into consideration during this study. Phytohormone auxin was found in Zambia, Ethiopia, and Tanzania, whereas cytokinin was found only in Mauritius as these countries were not found in the search results for one or other phytohormones (e.g., gibberellins, cytokinin, ethylene, etc.).

\begin{tabular}{|c|c|}
\hline Phytohormones & Common Countries \\
\hline Auxin & Zambia, Ethiopia, Tanzania \\
\hline Auxin and gibberellins & Jamaica \\
\hline Cytokinin & Mauritius \\
\hline Salicylic acid & Trinidad \& Tobago, Ghana, Jordan, Iraq \\
\hline Ethylene & $\begin{array}{c}\text { Qatar, Kuwait, Algeria, Portugal, Colombia, Chile, } \\
\text { Argentina, Ukraine }\end{array}$ \\
\hline Ethylene and salicylic acid & Lebanon, Finland, Greece, Romania \\
\hline Auxin and salicylic acid & Nepal \\
\hline Auxin and ethylene & Czechia, Hungary, Austria \\
\hline Auxin, cytokinin, ethylene, gibberellins & China \\
\hline Abscisic acid, auxin, ethylene, and salicylic acid & Thailand \\
\hline $\begin{array}{c}\text { Abscisic acid, auxin, cytokinin, ethylene, gibberellins, } \\
\text { and salicylic acid }\end{array}$ & $\begin{array}{c}\text { India, Philippines, Australia, Canada, United States, } \\
\text { United Kingdom }\end{array}$ \\
\hline Auxin, cytokinin, ethylene, gibberellins, and salicylic acid & Nigeria, Pakistan, Malaysia, Kenya, South Africa \\
\hline Auxin, ethylene, gibberellins, and salicylic acid & Spain \\
\hline Auxin, cytokinin, ethylene, and salicylic acid & New Zealand, Egypt, Poland \\
\hline Auxin, ethylene, and salicylic acid & $\begin{array}{c}\text { South Korea, Vietnam, Hong Kong, Sri Lanka, } \\
\text { Singapore, Taiwan, Bangladesh, Israel, United Arab } \\
\text { Emirates, Germany, Ireland, Sweden, Belgium, Iran, } \\
\text { Switzerland, Indonesia, Netherlands, Denmark, } \\
\text { Norway, Japan, Saudi Arabia, Italy, France, Mexico, } \\
\text { Brazil, Turkey, and Russia }\end{array}$ \\
\hline
\end{tabular}

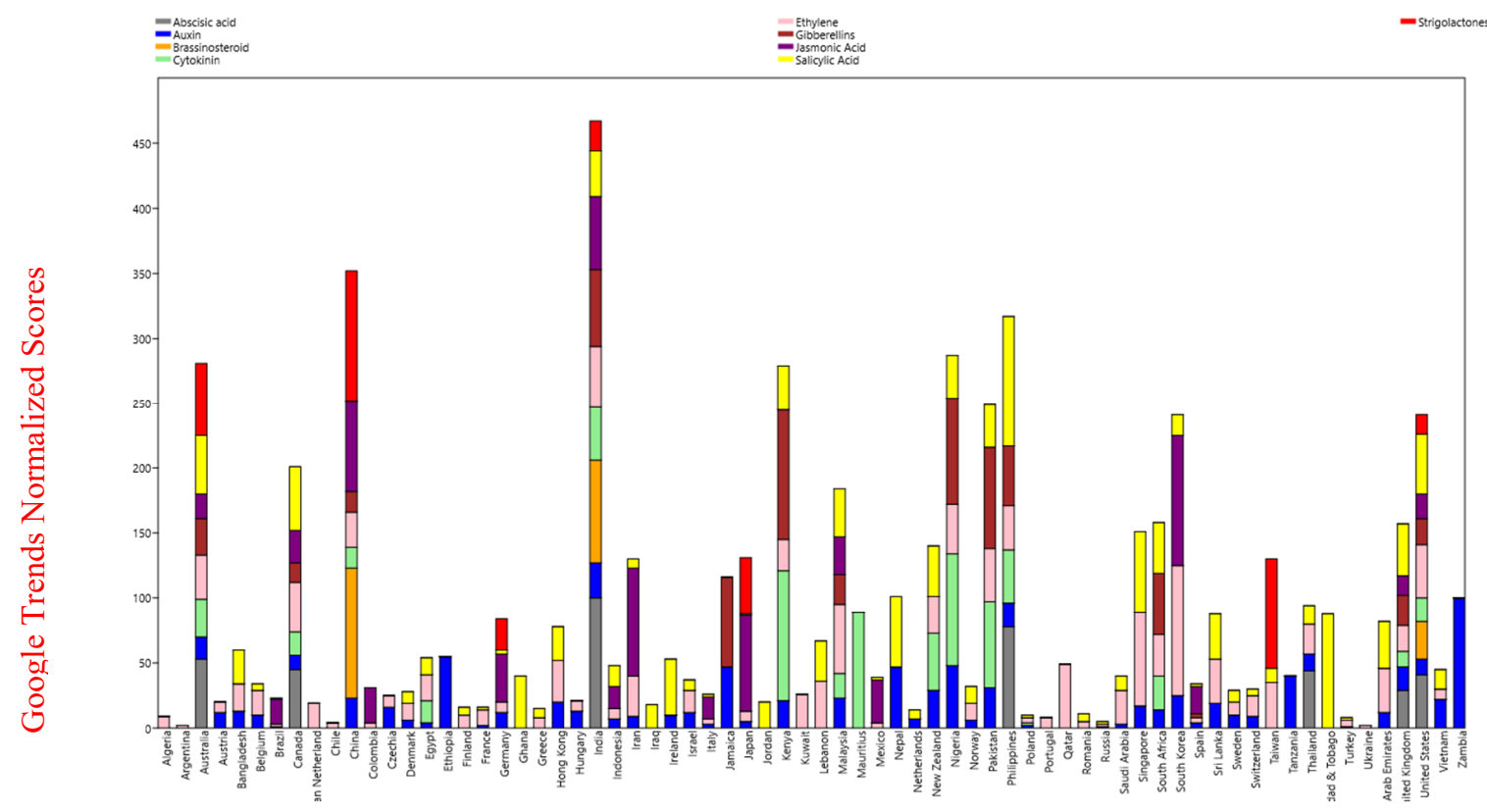

Figure 4. Stacking and area chart of phytohormone search of few countries. The data that resulted from the Google trend search was considered to draw the graph. From the figure, it can be observed that only India and the United States of America show nine stacks describing the search query for all the nine phytohormones. Australia has eight, China and the United Kingdom have seven, and the Philippines has six stacks, showing the respective phytohormone searches in these countries. 


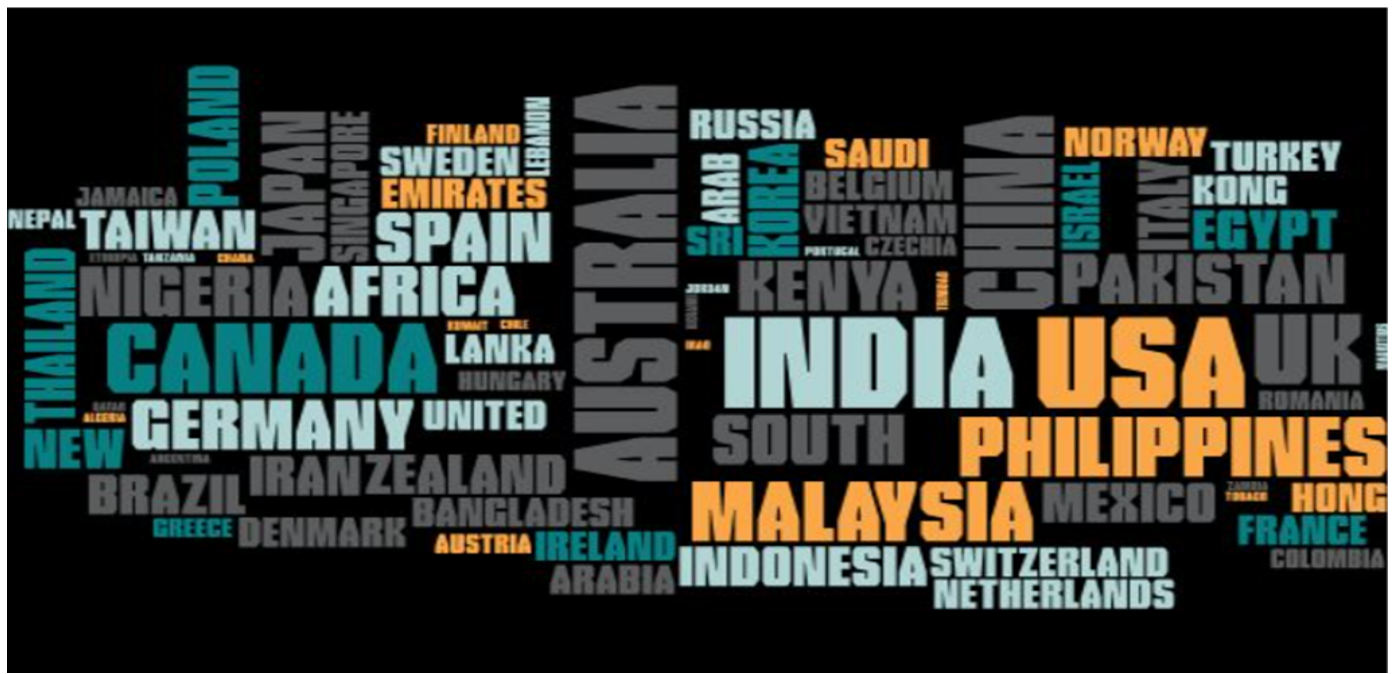

Figure 5. Word cloud of phytohormone search countries in the Google. The word cloud shows the most phytohormone search countries of the world. It includes India, the USA, United Kingdom, the Philippines, Australia, Kenya, Canada, and others. The word cloud was generated using the Google trend search for phytohormones for different countries.

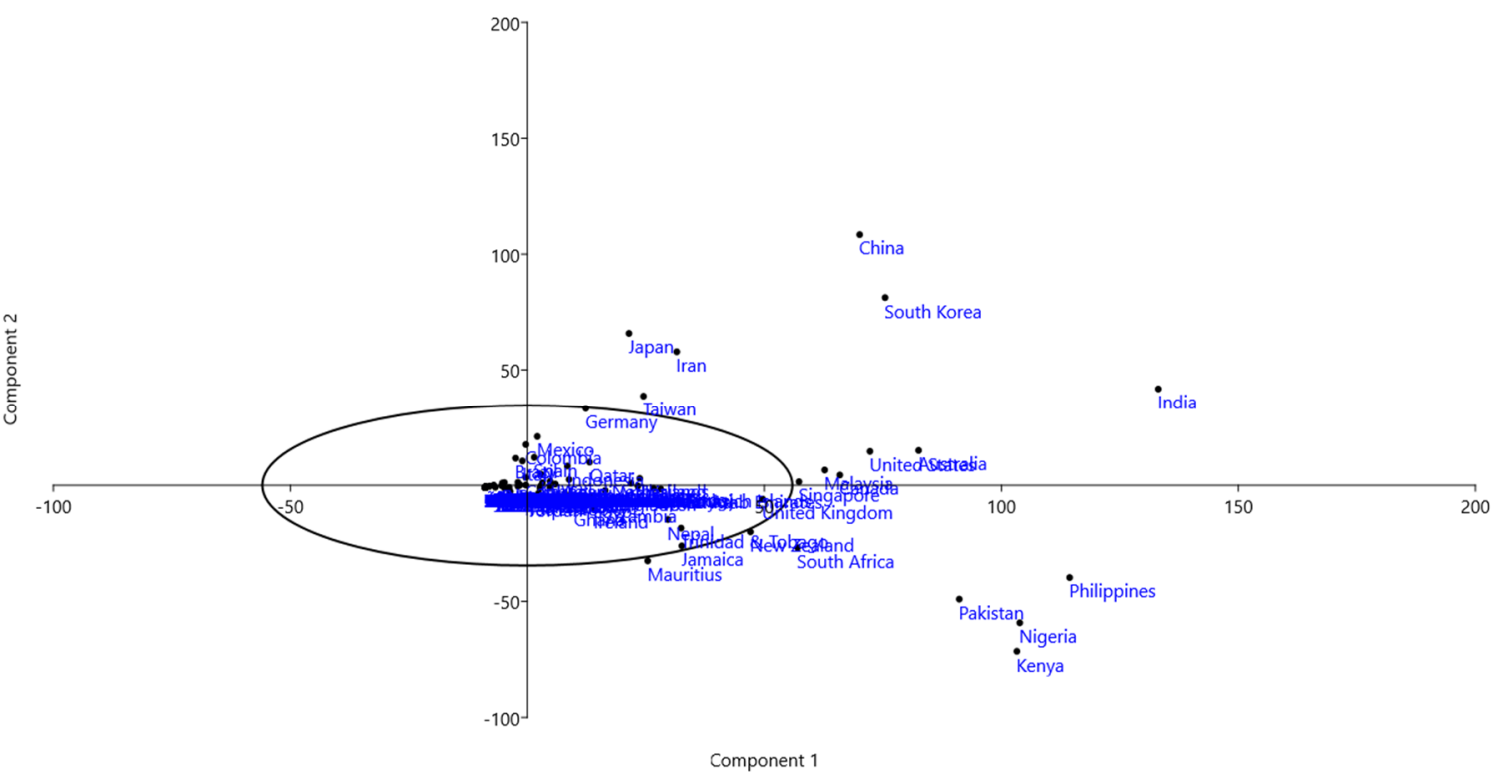

Figure 6. Principal component analysis (PCA) of all the countries associated with phytohormone search queries of all the nine studied phytohormones. PCA show India, United states, Australia, South Korea, China, Malaysia, Japan, etc. fall distantly in one coordinate whereas the Philippines, Nigeria, Kenya, Pakistan, the United Kingdom, South Africa, New Zealand, etc. fall distantly in another coordinate. The countries those fall distantly in the PCA plot show search queries for a greater number of phytohormones while those present in the center has none or zero result. The variance-covariance matrix was used to draw the PCA plot with 1000 bootstrap replicates. The Eigenvalue and variance of the PCA plot can be found in the supplementary data.

Clustering analysis revealed two major groups where India and China were in one group while the rest of the countries were in the other group (Figure 7). Within the latter cluster, Germany, Japan, and Iran grouped together; Austria, Hungary, Czechia, Belgium, Switzerland, Israel, Denmark, Israel, Denmark, Norway, Sweden; Kenya, Philippines, Nigeria, and Pakistan grouped together; Canada, UK, the USA, Malaysia, South Africa, New Zealand, and Singapore grouped together; and Bangladesh, 
Hong Kong, Sri Lanka, United Arab Emirates, and Lebanon grouped together; while South Korea grouped independently (Figure 7).

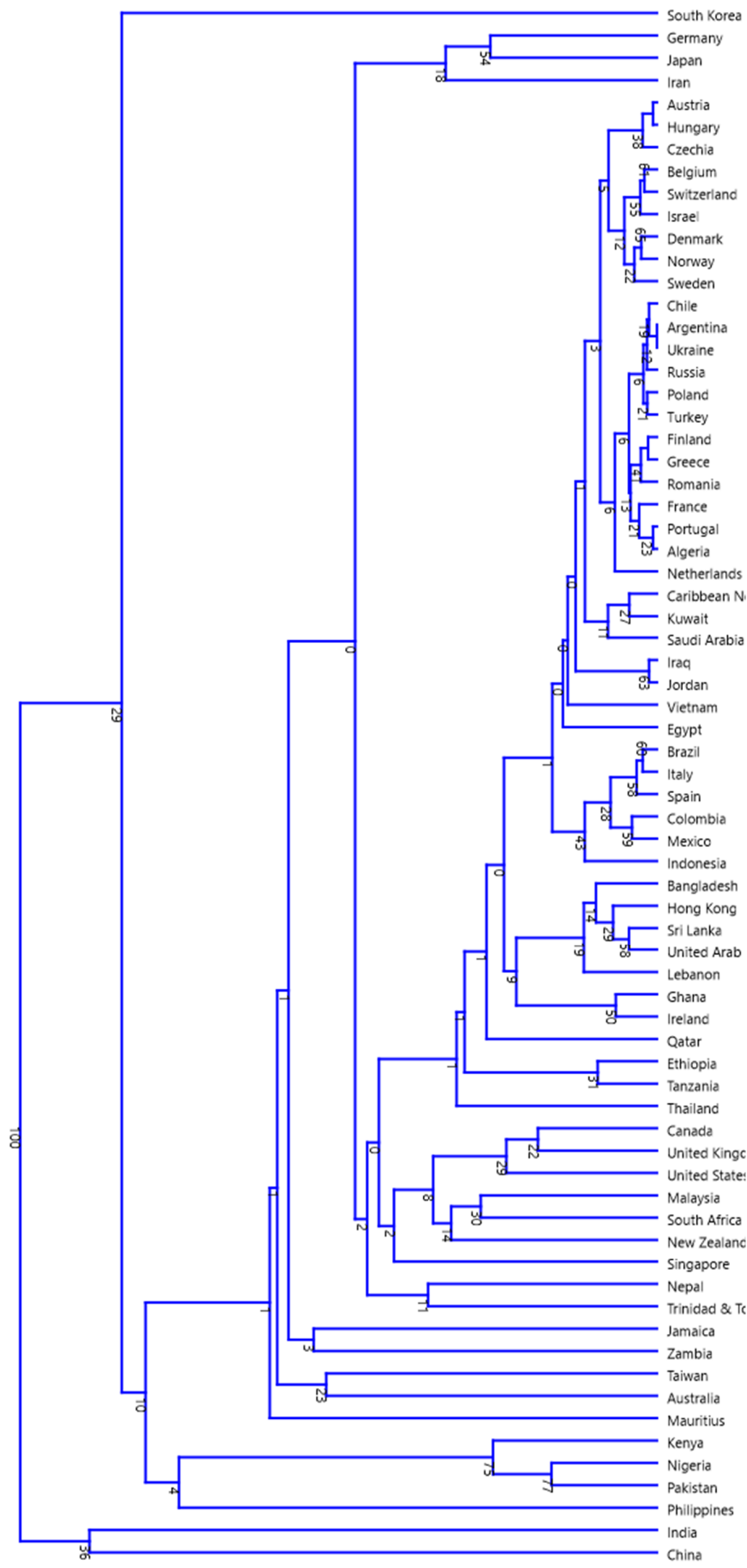

Figure 7. The neighbor- joining tree of the countries associated with phytohormone search. In the tree, India and China grouped together in one cluster, whereas South Korea fall alone in the other cluster. The African country Kenya and Nigeria grouped with Pakistan. Similarly, Germany, Japan, and Iran also fall in one group. 


\section{Discussion}

'Google Trends' data have been used to monitor real-time disease outbreaks and also further used to monitor the progression of the spread as well [46,49-51]. Google has been used by many people to diagnose different ailments prior to going to a doctor, and there has been a surge in the number of people searching for information related to health [52]. The use of 'Google Trends' is equally applicable to plant science, agriculture, and other allied subjects. Therefore, for the first time, we aimed to understand the global trends associated with "phytohormone" queries. It is commonly recognized that the USA, UK, Australia, Canada, China, Germany, France, Japan, Korea, Russia, and others are high-income countries and that agriculture production is also very high. The high level of agriculture production fosters a good economy and contributes significantly towards their national GDP (gross domestic product) [53,54]. Our 'Google Trends' analysis of phytohormone search queries from 2004-2019 revealed some interesting results. For instance, the African country Zambia, a least-developed country with a population of 17,861,030, had the greatest number of auxin search queries among 253 countries in the world. Other African countries, including Ethiopia, Nigeria, Jamaica, and Tanzania, also led the number of auxin search queries. Agriculture in Zambia contributes $19 \%$ to its GDP and employs three-quarters of the population [55]. The major agricultural products of Zambia are cassava, maize, millet, sorghum, soybean, groundnuts, rice, and cotton. Greater knowledge about trends in phytohormone search queries for Zambia may reflect and indicate research, production, manufacturing, and employment sector needs. The African country Kenya had the greatest number of cytokinin and gibberellin search queries globally, followed by Nigeria. Agriculture represents $26 \%$ of Kenya's GDP and provides more than $40 \%$ of the nation's employment [56]. The major agricultural products of Kenya are maize, wheat, and rice, which require advanced agricultural practices to attain high yields. Phytohormone search for cytokinin and gibberellin queries reflect the role that agricultural production plays in their society and its contribution towards the GDP of Kenya. Ethylene queries, however, were dominated by Asian countries, namely South Korea, followed by Singapore, Malaysia, Qatar, India, and Pakistan. Ethylene is a significant product that is made by chemical industries, and South Korea and Singapore are highly industrial. Hanwa Total, a petrochemical company, increased its ethylene production capacity by 30\% in 2017 [57]. Lotte Chemical estimated its ethylene production to be 200,000 tons per annum [58]. These chemical and petrochemical companies in South Korea may represent the major contributing factor for the highest number of ethylene queries globally. South Korea also had the greatest number of jasmonic acid queries globally. Jasmonic acid is associated with pest control, and hence jasmonic acid is used as a seed treatment for pest control in germinated seeds. The application of jasmonic acid induces the production of a protease inhibitor in plants that protects plants from insects $[59,60]$. The high number of jasmonic acid queries in South Korea may reflect the desire of people, farmers, and researchers in that country to produce pesticide-free crops. Iran and Japan also appear to be following the same principle. India had the greatest number of abscisic acid queries globally. Approximately $18 \%$ of India's GDP is generated by the agriculture sector and provides 50\% of the nation's employment [61]. A major portion of the Indian economy is dependent on agriculture, and the high number of queries on all nine phytohormones may reflect the role agriculture plays in the economy of India. Similar relationships can be stated for Malaysia and Pakistan. These latter countries are developing countries and their economy largely depends on the agricultural sector. The greatest number of abscisic acid search queries was concentrated in the countries of the South Asian sub-continent. Abscisic acid triggers the closure of stomata and is, thus a signal which can minimize transpiration. Farmers often use applications of abscisic acid to reduce the rate of transpiration and avoid drought stress. As India, the Philippines, and Thailand are tropical and sub-tropical climates, as well as Australia, to some extent, the crops in this region exhibit high transpiration rates and, thus abscisic acid use occurs maximally in this region to limit drought stress and maintain crop productivity. China had the greatest number of brassinosteroids queries globally. Notably, brassinosteroids play a prominent role in the physiology of horticultural crops. BRs have the potential to increase the quantity and quality of horticultural crops and also increase stress tolerance [62]. 
Therefore, it is considered as a plant "strengthening substance". The application of brassinosteroids may contribute to making China one of the top five global producers of buckwheat, maize, millet, rice, wheat, potato, sugarcane, grapes, apple, sunflower, orange, and banana. Similarly, but lower numbers of brassinosteroids queries were observed for India and the United States. China also had the greatest number of strigolactones queries globally. Strigolactones play a critical role in establishing the symbiotic relationship between arbuscular mycorrhizae and the roots of their plant hosts. The symbiotic relationship provides nutrients, especially phosphate, from the soil to plants. Therefore, arbuscular mycorrhizae are currently used to a large extent in animal manures used to fertilize plants and help enhance crop productivity in sustainable agricultural systems. China is focusing more on the use of organic composts in sustainable agricultural management systems to produce organic green vegetable crops $[63,64]$. In addition, strigolactones are also used for seed germination $[65,66]$. Being a larger agriculture producing country, China might be using strigolactones to enhance the seed germination potential of the seeds. The Philippines had the greatest number of salicylic acid queries globally, followed by Trinidad \& Tobago, Singapore, Nepal, Canada, the USA, Australia, and others.

\section{Conclusions}

'Google Trends' gives us geographic information of different countries who have searched a particular term in Google. Data on the information-seeking activity of people in different countries provides a wealth of useful knowledge on the needs, economy, health, and trending prospects of individual countries. Data obtained on phytohormone queries in the developing country of Zambia is a classic example of how unexpected trends can be observed. The study indicated that African countries have a greater interest in searching for information on phytohormones than American or European countries. This study can be utilized further by the Food and Agriculture Organization (FAO) and other organizations that are involved in the development of agriculture practice in African and Asian subcontinents. Although Google trend search is a valuable search engine, it also suffers with a few limitations. Google trends only compares the keywords rather than providing any objective indication on the absolute number of popularities of a particular term. On Google trend, we cannot find exactly how many people searched for a particular word in a specified time period, thus provides a relative number of searches. Some search terms might not be displayed due to lower search quota, which might not be negligible for absolute number. The statistical robustness of the Google trend data can be increased by increasing the repetition of searches. The spatial and temporal scales also represent the magnitude of the searches, and hence the limitation can be acceptable.

\section{Materials and Methods}

\subsection{Data Collection}

The current study was conducted using time series data on query searches beginning from the start of the time that Google began to collect such data (1 January 2004) to the present time (20 October 2019). It resulted in Google trend results according to different countries over the mentioned time period. We downloaded queries made separately on nine different phytohormones using 'Google Trends' and downloaded the data as an csv file, and then merged all of the data into a single Excel file to conduct a comparative analysis. The analysis of nine phytohormone queries included abscisic acid, auxin, brassinosteroids, cytokinin, ethylene, gibberellin, jasmonic acid, salicylic acid, and strigolactones. Each plant hormone was searched individually using the exact text as mentioned, and neither alternative or any synonymous term, was used in this study. We analyzed the data on each of the phytohormones based on country. Each csv file covered 253 countries, but only data from countries that showed a significant number of search queries in the Google search engine were included. In each csv file of the data, 100 was used to represent the highest number of queries, while 0 represented the lowest number of searches in Google. Google trend only provides relative data and does not provide any absolute search data, and hence all the study explained in the manuscript is associated with the relative data. 


\subsection{Data Normalization}

Increases in the number of search queries increased its own average over a period of time and hence served as the denominator for later comparisons. This reduced the sensitivity in the detection of changes in search trends based on search volume. 'Google Trends' controls the bias created by unrelated common search queries. For example, the search term "disease" may be normalized by dividing its' number by the search volume of the unrelated search term, "music". Normalization also compensated for the population size of a region, thus making it possible to rank the countries purely on the basis of search volume. For example, if the proportion of the Indian population using the query term "music" is the same as the proportion of Bangladesh, the effect of the larger population of India was factored out.

To rank the top countries, 'Google Trends' takes a sample of all search queries made on the web and determines the area from which most of the queries originated. The internet protocol (IP) address was used to establish the origin of the web queries by analyzing the server logs. An algorithm later calculates the ratio of a variable's search volume from each country, and the total search volume from each country.

\subsection{Statistical Analysis}

Time-wise and country-wise 'Google Trends' data were collected for each of nine individual phytohormones. To analyze the trends for each of the different phytohormone search terms, monthly data for all of the phytohormones were place in an Excel file (MS Excel 2016) and used to generate a line graph. The resulting country-based search data were used for principal component analysis (PCA) using freely-available Past3 software (https://www.techworld.com/download/office-business/past-314-333082 1/). Multivariate linear regression analysis was conducted using Past3 software. A variance-covariance model was used to construct the PCA plot with 1000 bootstrap replicates. The same file was later used to construct a cluster graph to illustrate closely related/grouped countries for each search term using the paired group UPGMA method with the Euclidean similarity index, and 1000 bootstrap replicates. A stacked bar plot was also created using the Past3 software. A frequency plot and statistical analysis of all the nine plant hormones were conducted using the Prism software version 6 . The graphical map of search queries for each of the nine different phytohormones was downloaded from 'Google Trends'.

A Venn diagram was constructed in order to illustrate which countries were associated in common with a phytohormone search term. The Venn diagram was constructed using InteractiveVenn (http://www.interactivenn.net/) software [67].

Supplementary Materials: The following are available online at http://www.mdpi.com/2223-7747/9/9/1248/s1. Supplementary Figure S1. Google trend graph of phytohormone abscisic acid, auxin, brassinosteroids, cytokinin, gibberellin, Jasmonic acid, salicylic acid, ethylene, and strigolactones. The data were ranged from 1 January 2004 to 20 October 2019, Supplementary Figure S2. Venn diagram showing the common countries with common phytohormone search queries. At the center of the of diagram showing 6 depicts all the six phytohormone search found in India, Philippines, United Kingdom, Australia, United States, and Canada. Similarly, number 5 depicts five phytohormones auxin, gibberellins, cytokinin, salicylic acid, and ethylene was found in Nigeria, Pakistan, Malaysia, Kenya, and South Africa. Auxin, salicylic acid and ethylene search were found in 27 countries; auxin and ethylene search were found in three countries Czechia, Hungary, and Austria; auxin, cytokinin, salicylic acid, and ethylene search was common in three countries New Zealand, Egypt, and Poland. Supplementary Figure S3. Multivariate linear regression (1 independent, $n$ dependent) analysis of different phytohormones searched in Google, Supplementary File 1. Google trends data of abscisic acid, Supplementary File 2. Google trends data of auxin, Supplementary File 3. Google trends data of brassinosteroids, Supplementary File 4. Google trends data of cytokinin, Supplementary File 5. Google trends data of ethylene, Supplementary File 6. Google trends data of gibberellins, Supplementary File 7. Google trends data of Jasmonic acid, Supplementary File 8. Google trends data of salicylic acid, Supplementary File 9. Google trends data of strigolactones, Supplementary File 10. Google trend data of all the phytohormones merged to construct a graph, Supplementary File 11. Venn diagram result of the Google trend phytohormone analysis.

Author Contributions: T.K.M., Conceived the idea, extracted, analyzed, and interpreted the data, drafted and revised the manuscript, Y.K.M. and D.Y., Analyzed the data; A.H., E.F.A., and A.A.-H., revised the manuscript. All authors have read and agreed to the published version of the manuscript. 
Funding: This research received no external funding.

Acknowledgments: The authors would like to extend their sincere appreciation to the Researchers Supporting Project Number (RSP-2020/134), King Saud University, Riyadh, Saudi Arabia.

Conflicts of Interest: There is no competing interest to declare.

Consent for Publication: All authors agree and provide consent for publication.

Availability of Data: All of the data utilized in this study were obtained from the publicly-available 'Google Trends' search engine. Data associated with the manuscript is provided in supplementary files.

\section{References}

1. Mohanta, T.K.; Mohanta, N.; Bae, H. Identification and Expression Analysis of PIN-Like (PILS) Gene Family of Rice Treated with Auxin and Cytokinin. Genes 2015, 6, 622-640. [CrossRef] [PubMed]

2. Mohanta, T.K.; Bashir, T.; Hashem, A.; Abd_Allah, E.F.; Khan, A.L.; Al-Harrasi, A.S. Early Events in Plant Abiotic Stress Signaling: Interplay Between Calcium, Reactive Oxygen Species and Phytohormones. J. Plant Growth Regul. 2018, 37, 1033-1049. [CrossRef]

3. Gururani, M.A.; Mohanta, T.K.; Bae, H. Current Understanding of the Interplay between Phytohormones and Photosynthesis under Environmental Stress. Int. J. Mol. Sci. 2015, 16, 19055-19085. [CrossRef] [PubMed]

4. Singh, P.; Mohanta, T.K.; Sinha, A.K. Unraveling the intricate nexus of molecular mechanisms governing rice root development: OsMPK3/6 and auxin-cytokinin interplay. PLoS ONE 2015, 10, e0123620. [CrossRef]

5. Ahmad, P.; Rasool, S.; Gul, A.; Sheikh, S.A.; Akram, N.A.; Ashraf, M.; Kazi, A.M.; Gucel, S. Jasmonates: Multifunctional Roles in Stress Tolerance. Front. Plant Sci. 2016, 7, 813. [CrossRef]

6. Davies, P.J. The Plant Hormones: Their Nature, Occurrence, and Functions. In Plant Hormones; Davies, P.J., Ed.; Springer: Dordrecht, The Netherlands, 2010; pp. 1-15, ISBN 978-1-4020-2686-7.

7. Miransari, M.; Smith, D.L. Plant hormones and seed germination. Environ. Exp. Bot. 2014, 99, $110-121$. [CrossRef]

8. Tanimoto, E. Regulation of Root Growth by Plant Hormones-Roles for Auxin and Gibberellin. Crit. Rev. Plant Sci. 2005, 24, 249-265. [CrossRef]

9. Voesenek, L.A.C.J.; Rijnders, J.H.G.M.; Peeters, A.J.M.; van de Steeg, H.M.; de Kroon, H. Plant Hormones Regulate Fast Shoot Elongation under Water: From Genes to Communities. Ecology 2004, 85, 16-27. [CrossRef]

10. Bar, M.; Ori, N. Leaf development and morphogenesis. Development 2014, 141, 4219-4230. [CrossRef]

11. Emery, R.J.N.; Longnecker, N.E.; Atkins, C.A. Branch development in Lupinus angustifolius L. II. Relationship with endogenous ABA, IAA and cytokinins in axillary and main stem buds. J. Exp. Bot. 1998, 49, 555-562. [CrossRef]

12. Metzger, J.D. Plant Hormones: Physiology, Biochemistry and Molecular Biology. In Hormones and Reproductive Development; Davies, P.J., Ed.; Springer: Dordrecht, The Netherlands, 1995; pp. 617-648, ISBN 978-94-011-0473-9.

13. Nitsch, J.P. Plant Hormones in the Development of Fruits. Q. Rev. Biol. 1952, 27, 33-57. [CrossRef] [PubMed]

14. Kumar, R.; Khurana, A.; Sharma, A.K. Role of plant hormones and their interplay in development and ripening of fleshy fruits. J. Exp. Bot. 2014, 65, 4561-4575. [CrossRef] [PubMed]

15. Srivastava, M.K.; Dwivedi, U.N. Delayed ripening of banana fruit by salicylic acid. Plant Sci. 2000, 158, 87-96. [CrossRef]

16. Vidya Vardhini, B.; Rao, S.S.R. Acceleration of ripening of tomato pericarp discs by brassinosteroids. Phytochemistry 2002, 61, 843-847. [CrossRef]

17. Joo, J.H.; Bae, Y.S.; Lee, J.S. Role of Auxin-Induced Reactive Oxygen Species in Root Gravitropism. Plant Physiol. 2001, 126, 1055-1060. [CrossRef]

18. Marchant, A.; Kargul, J.; May, S.T.; Muller, P.; Delbarre, A.; Perrot-Rechenmann, C.; Bennett, M.J. AUX1 regulates root gravitropism in Arabidopsis by facilitating auxin uptake within root apical tissues. EMBO J. 1999, 18, 2066-2073. [CrossRef]

19. Moore, I. Gravitropism: Lateral Thinking in Auxin Transport. Curr. Biol. 2002, 12, R452-R454. [CrossRef]

20. Band, L.R.; Wells, D.M.; Larrieu, A.; Sun, J.; Middleton, A.M.; French, A.P.; Brunoud, G.; Sato, E.M.; Wilson, M.H.; Péret, B.; et al. Root gravitropism is regulated by a transient lateral auxin gradient controlled by a tipping-point mechanism. Proc. Natl. Acad. Sci. USA 2012, 109, 4668-4673. [CrossRef] 
21. Tarakhovskaya, E.R.; Maslov, Y.I.; Shishova, M.F. Phytohormones in algae. Russ. J. Plant Physiol. 2007, 54, 163-170. [CrossRef]

22. Kiseleva, A.A.; Tarachovskaya, E.R.; Shishova, M.F. Biosynthesis of phytohormones in algae. Russ. J. Plant Physiol. 2012, 59, 595-610. [CrossRef]

23. Araújo, F.F.; Henning, A.A.; Hungria, M. Phytohormones and Antibiotics Produced by Bacillus subtilis and their Effects on Seed Pathogenic Fungi and on Soybean Root Development. World J. Microbiol. Biotechnol. 2005, 21, 1639-1645. [CrossRef]

24. Tudzynski, B. Fungal Phytohormones in Pathogenic and Mutualistic Associations. In Plant Relationships; Carroll, G.C., Tudzynski, P., Eds.; Springer: Berlin/Heidelberg, Germany, 1997; pp. 167-184, ISBN 978-3-662-10370-8.

25. Tudzynski, B.; Sharon, A. Biosynthesis, Biological Role and Application of Fungal Phytohormones. In Industrial Applications; Osiewacz, H.D., Ed.; Springer: Berlin/Heidelberg, Germany, 2002; pp. 183-211, ISBN 978-3-662-10378-4.

26. Costacurta, A.; Vanderleyden, J. Synthesis of Phytohormones by Plant-Associated Bacteria. Crit. Rev. Microbiol. 1995, 21, 1-18. [CrossRef] [PubMed]

27. Tsavkelova, E.A.; Cherdyntseva, T.A.; Netrusov, A.I. Auxin production by bacteria associated with orchid roots. Microbiology 2005, 74, 46-53. [CrossRef]

28. Shahid, M.; Khan, M.S. Cellular destruction, phytohormones and growth modulating enzymes production by Bacillus subtilis strain BC8 impacted by fungicides. Pestic. Biochem. Physiol. 2018, 149, 8-19. [CrossRef]

29. Kalra, G.; Bhatla, S.C. Abscisic Acid. In Plant Physiology, Development and Metabolism; Bhatla, S.C., Lal, A.M., Eds.; Springer: Singapore, 2018; pp. 629-641, ISBN 978-981-13-2023-1.

30. Addicott, F.T.; Lyon, J.L.; Ohkuma, K.; Thiessen, W.E.; Carns, H.R.; Smith, O.E.; Cornforth, J.W.; Milborrow, B.V.; Ryback, G.; Wareing, P.F. Abscisic Acid: A New Name for Abscisin II (Dormin). Science 1968, 159, 1493. [CrossRef]

31. Kurepin, L.V.; Zaman, M.; Pharis, R.P. Phytohormonal basis for the plant growth promoting action of naturally occurring biostimulators. J. Sci. Food Agric. 2014, 94, 1715-1722. [CrossRef]

32. Khan, A.; Bilal, S.; Khan, A.L.; Imran, M.; Shahzad, R.; Al-Harrasi, A.; Al-Rawahi, A.; Al-Azhri, M.; Mohanta, T.K.; Lee, I.-J. Silicon and Gibberellins: Synergistic Function in Harnessing ABA Signaling and Heat Stress Tolerance in Date Palm (Phoenix dactylifera L.). Plants 2020, 9, 620. [CrossRef]

33. Passioura, J.B. Environmental biology and crop improvement. Funct. Plant Biol. 2002, 29, 537-546. [CrossRef]

34. Daughtrey, M.L.; Benson, D.M. Principles of Plant Health Management for Ornamental Plants. Annu. Rev. Phytopathol. 2005, 43, 141-169. [CrossRef]

35. Sakamoto, T. Phytohormones and rice crop yield: Strategies and opportunities for genetic improvement. Transgenic Res. 2006, 15, 399-404. [CrossRef]

36. Larrigaudiere, C.; Guillen, P.; Vendrell, M. Harvest maturity related changes in the content of endogenous phytohormones and quality parameters of melon. Postharvest Biol. Technol. 1995, 6, 73-80. [CrossRef]

37. Clendennen, S.K.; Kipp, P.B.; May, G.D. The Role of Ethylene in Banana Fruit Ripening. In Biology and Biotechnology of the Plant Hormone Ethylene; Kanellis, A.K., Chang, C., Kende, H., Grierson, D., Eds.; Springer: Dordrecht, The Netherlands, 1997; pp. 141-148, ISBN 978-94-011-5546-5.

38. Koukourikou-Petridou, M.A. Etiolation of stock plants affects adventitious root formation and hormone content of pea stem cuttings. Plant Growth Regul. 1998, 25, 17-21. [CrossRef]

39. Zahir, Z.A.; Arshad, M.; Azam, M.; Hussain, A. Effect of an auxin precursor tryptophan and Azotobacter inoculation on yield and chemical composition of potato under fertilized conditions. J. Plant Nutr. 1997, 20, 745-752. [CrossRef]

40. Stirk, W.A.; Van Staden, J. Comparison of cytokinin- and auxin-like activity in some commercially used seaweed extracts. J. Appl. Phycol. 1996, 8, 503-508. [CrossRef]

41. FAOSTAT. Food and Agriculture Organization of the United Nations. 2016. Available online: http: //www.fao.org/faostat/en/\#rankings/countries_by_commodity (accessed on 5 January 2020).

42. Choi, H.; Varian, H.A.L. Predicting the Present with Google Trends. Econ. Rec. 2012, 88, 2-9. [CrossRef]

43. Polykalas, S.E.; Prezerakos, G.N.; Konidaris, A. An algorithm based on Google Trends' data for future prediction. Case study: German elections. In IEEE International Symposium on Signal Processing and Information Technology; IEEE: Piscataway Township, NJ, USA, 2013; pp. 69-73. 
44. Cocco, A.M.; Zordan, R.; Taylor, M.D.; Weiland, T.J.; Dilley, T.J.; Kant, J.; Dombgolla, M.; Hendarto, A.; Lai, F.; Hutton, J. Dr Google in the ED: Searching for online health information by adult emergency department patients. Med. J. Aust. 2018, 209, 342-347. [CrossRef]

45. Arora, V.S.; McKee, M.; Stuckler, D. Google Trends: Opportunities and limitations in health and health policy research. Health Policy 2019, 123, 338-341. [CrossRef]

46. Husnayain, A.; Fuad, A.; Lazuardi, L. Correlation between Google Trends on dengue fever and national surveillance report in Indonesia. Glob. Health Action 2019, 12, 1552652. [CrossRef]

47. Polgreen, P.M.; Chen, Y.; Pennock, D.M.; Nelson, F.D. Using Internet Searches for Influenza Surveillance. Clin. Infect. Dis. 2008, 47, 1443-1448. [CrossRef]

48. Nuti, S.V.; Wayda, B.; Ranasinghe, I.; Wang, S.; Dreyer, R.P.; Chen, S.I.; Murugiah, K. The use of google trends in health care research: A systematic review. PLoS ONE 2014, 9, e109583. [CrossRef]

49. Chan, E.H.; Sahai, V.; Conrad, C.; Brownstein, J.S. Using web search query data to monitor dengue epidemics: A new model for neglected tropical disease surveillance. PLoS Negl. Trop. Dis. 2011, 5, e1206. [CrossRef] [PubMed]

50. Guo, P.; Wang, L.; Zhang, Y.; Luo, G.; Zhang, Y.; Deng, C.; Zhang, Q.; Zhang, Q. Can internet search queries be used for dengue fever surveillance in China? Int. J. Infect. Dis. 2017, 63, 74-76. [CrossRef] [PubMed]

51. Carneiro, H.A.; Mylonakis, E. Google Trends: A Web-Based Tool for Real-Time Surveillance of Disease Outbreaks. Clin. Infect. Dis. 2009, 49, 1557-1564. [CrossRef] [PubMed]

52. Kirk, A. One in Four Self-Diagnose on the Internet instead of Visiting the Doctor. The Telegraph. Available online: https://www.telegraph.co.uk/news/health/news/11760 (accessed on 24 July 2015).

53. Gadgil, S.; Gadgil, S. The Indian Monsoon, GDP and Agriculture. Econ. Political Wkly. 2006, 41, 4887-4895.

54. Abimanyu, A. Impact of Agriculture Trade and Subsidy Policy on the Macroeconomy, Distribution, and Environment in Indonesia: A Strategy for Future Industrial Development. Dev. Econ. 2000, 38, 547-571. [CrossRef]

55. Export.Gov. Zambia-Agricultural Sector. 2019. Available online: https://www.export.gov/apex/article2?id= Zambia-Agricultural-Sector (accessed on 4 April 2019).

56. The Agriculture Sector in Kenya. Available online: http://www.fao.org/kenya/fao-in-kenya/kenya-at-a-glan ce/en/\#: \{\}:text=Agriculture $\% 20 \mathrm{is} \% 20 \mathrm{key} \% 20$ to $\% 20$ Kenya $\backslash \mathrm{T} 1 \backslash$ textquoterights, cent $\% 20 \mathrm{of} \% 20 \mathrm{Kenya} \backslash \mathrm{T} 1 \mid$ tex tquoterights\%20rural\%20people (accessed on 5 January 2020).

57. Moon, I.; Hyun Cho, J. The chemical industry of South Korea: Progress and challenges. Chem. Eng. Prog. 2011, 107, 40-45.

58. Lotte Chemical to Increase Ethylene Production Capacity in South Korea. Available online: https://www.tech sciresearch.com/news/2135-lotte-chemical-to-increase-ethylene-production-capacity-in-south-korea.html (accessed on 5 January 2020).

59. Koiwa, H.; Bressan, R.A.; Hasegawa, P.M. Regulation of protease inhibitors and plant defense. Trends Plant Sci. 1997, 2, 379-384. [CrossRef]

60. Farmer, E.E.; Ryan, C.A. Octadecanoid Precursors of Jasmonic Acid Activate the Synthesis of Wound-Inducible Proteinase Inhibitors. Plant Cell 1992, 4, 129-134. [CrossRef]

61. Bhasker, G.V. Agriculture Role of Indian Economy. Int. J. Trend Sci. Res. Dev. 2017, 1, 1066-1067. [CrossRef]

62. Kang, Y.Y.; Guo, S.R. Role of brassinosteroids on horticultural crops. In Brassinosteroids: A Class of Plant Hormone; Hayat, S., Ahmad, A., Eds.; Springer: Dordrecht, The Netherlands, 2011; pp. 269-288, ISBN 978-94-007-0189-2.

63. Luo, X.; Liu, G.; Xia, Y.; Chen, L.; Jiang, Z.; Zheng, H.; Wang, Z. Use of biochar-compost to improve properties and productivity of the degraded coastal soil in the Yellow River Delta, China. J. Soils Sediments 2017, 17, 780-789. [CrossRef]

64. Cai, Z.C.; Qin, S.W. Dynamics of crop yields and soil organic carbon in a long-term fertilization experiment in the Huang-Huai-Hai Plain of China. Geoderma 2006, 136, 708-715. [CrossRef]

65. Brun, G.; Braem, L.; Thoiron, S.; Gevaert, K.; Goormachtig, S.; Delavault, P. Seed germination in parasitic plants: What insights can we expect from strigolactone research? J. Exp. Bot. 2017, 69, 2265-2280. [CrossRef] [PubMed] 
66. Matusova, R.; Rani, K.; Verstappen, F.W.A.; Franssen, M.C.R.; Beale, M.H.; Bouwmeester, H.J. The Strigolactone Germination Stimulants of the Plant-Parasitic Striga and Orobanche spp. Are Derived from the Carotenoid Pathway. Plant Physiol. 2005, 139, 920-934. [CrossRef] [PubMed]

67. Heberle, H.; Meirelles, G.V.; da Silva, F.R.; Telles, G.P.; Minghim, R. InteractiVenn: A web-based tool for the analysis of sets through Venn diagrams. BMC Bioinform. 2015, 16, 169. [CrossRef] [PubMed]

(C) 2020 by the authors. Licensee MDPI, Basel, Switzerland. This article is an open access article distributed under the terms and conditions of the Creative Commons Attribution (CC BY) license (http://creativecommons.org/licenses/by/4.0/). 